\title{
Evaluating Tumor Response of Non-Small Cell Lung Cancer Patients With F-18-Fludeoxyglucose Positron Emission Tomography: Potential for Treatment Individualization
}

Citation for published version (APA):

Toma-Dasu, I., Uhrdin, J., Lazzeroni, M., Carvalho, S., van Elmpt, W., Lambin, P., \& Dasu, A. (2015). Evaluating Tumor Response of Non-Small Cell Lung Cancer Patients With F-18-Fludeoxyglucose Positron Emission Tomography: Potential for Treatment Individualization. International Journal of Radiation Oncology Biology Physics, 91(2), 376-384. https://doi.org/10.1016/j.ijrobp.2014.10.012

Document status and date:

Published: 01/02/2015

DOI:

10.1016/j.jijrobp.2014.10.012

Document Version:

Publisher's PDF, also known as Version of record

Document license:

Taverne

Please check the document version of this publication:

- A submitted manuscript is the version of the article upon submission and before peer-review. There can be important differences between the submitted version and the official published version of record. People interested in the research are advised to contact the author for the final version of the publication, or visit the DOI to the publisher's website.

- The final author version and the galley proof are versions of the publication after peer review.

- The final published version features the final layout of the paper including the volume, issue and page numbers.

Link to publication

\footnotetext{
General rights rights.

- You may freely distribute the URL identifying the publication in the public portal. please follow below link for the End User Agreement:

www.umlib.nl/taverne-license

Take down policy

If you believe that this document breaches copyright please contact us at:

repository@maastrichtuniversity.nl

providing details and we will investigate your claim.
}

Copyright and moral rights for the publications made accessible in the public portal are retained by the authors and/or other copyright owners and it is a condition of accessing publications that users recognise and abide by the legal requirements associated with these

- Users may download and print one copy of any publication from the public portal for the purpose of private study or research.

- You may not further distribute the material or use it for any profit-making activity or commercial gain

If the publication is distributed under the terms of Article 25fa of the Dutch Copyright Act, indicated by the "Taverne" license above,

Download date: 26 Apr. 2023 


\title{
Evaluating Tumor Response of Non-Small Cell Lung Cancer Patients With ${ }^{18} \mathrm{~F}$-Fludeoxyglucose Positron Emission Tomography: Potential for Treatment Individualization
}

\author{
Iuliana Toma-Dasu, PhD, ${ }^{*}$ Johan Uhrdin, $\mathrm{MSc}^{\dagger}$ Marta Lazzeroni, $\mathrm{PhD}$, \\ Sara Carvalho, MSc, ${ }^{\S}$ Wouter van Elmpt, PhD, Philippe Lambin, PhD, \\ and Alexandru Dasu, PhD
}

\author{
${ }^{*}$ Medical Radiation Physics, Stockholm University and Karolinska Institutet, Stockholm; ${ }^{\dagger}$ RaySearch \\ Laboratories AB, Stockholm; ${ }^{\ddagger}$ Medical Radiation Physics, Karolinska Institutet, Stockholm; \\ ${ }^{\S}$ Department of Radiation Oncology, GROW-School for Oncology and Developmental Biology, \\ Maastricht University Medical Center, Maastricht, The Netherlands; and "Department of Radiation \\ Physics and Department of Medical and Health Sciences, Linköping University, Linköping, Sweden
}

Received Jul 18, 2014, and in revised form Sep 19, 2014. Accepted for publication Oct 7, 2014.

\section{Summary \\ Tumor responsiveness and the corresponding effective radiosensitivity were assessed for individual pa- tients with non-small cell lung cancer, based on 2 suc- cessive ${ }^{18} \mathrm{~F}$-fludeoxyglucose positron emission tomogra- phy scans. The results showed that it is feasible to determine a threshold value of the average effective radiosensitivity in the pri- mary gross target volume but not in the lymph node gross}

\begin{abstract}
Objective: To assess early tumor responsiveness and the corresponding effective radiosensitivity for individual patients with non-small cell lung cancer (NSCLC) based on 2 successive ${ }^{18}$ F-fludeoxyglucose positron emission tomography (FDG-PET) scans. Methods and Materials: Twenty-six NSCLC patients treated in Maastricht were included in the study. Fifteen patients underwent sequential chemoradiation therapy, and 11 patients received concomitant chemoradiation therapy. All patients were imaged with FDG before the start and during the second week of radiation therapy. The sequential images were analyzed in relation to the dose delivered until the second image. An operational quantity, effective radiosensitivity, $\alpha_{e f f}$, was determined at the voxel level. Correlations were sought between the average $\alpha_{\text {eff }}$ or the fraction of negative $\alpha_{\text {eff }}$ values and the overall survival at 2 years. Separate analyses were performed for the primary gross target volume (GTV), the lymph node GTV, and the clinical target volumes (CTVs).

Results: Patients receiving sequential treatment could be divided into responders and nonresponders, using a threshold for the average $\alpha_{\text {eff }}$ of $0.003 \mathrm{~Gy}^{-1}$ in the primary GTV, with a sensitivity of $75 \%$ and a specificity of $100 \%(P<.0001)$. Choosing the fraction of negative $\alpha_{\text {eff }}$ as a criterion, the threshold 0.3 also had a sensitivity of $75 \%$

Health (NIH-USA U01 CA 143062-01, Radiomics of NSCLC); EU 7th framework program (EURECA, ARTFORCE); euroCAT (IVA Interreg www.eurocat.info); Kankeronderzoekfonds Limburg from the Health Foundation Limburg and the Dutch Cancer Society (KWF UM 2009-4454, KWF MAC 2013-6425); and the Cancer Research Funds of Radiumhemmet.

Conflict of interest: none.
\end{abstract}

Reprint requests to: Iuliana Toma-Dasu, PhD, Medical Radiation Physics, Stockholm University and Karolinska Institutet, Box 260, S-171 76 Stockholm, Sweden. Tel: (+46) 8-5177 4839; E-mail: Iuliana.Livia. Dasu@ki.se

Supported by the QuIC-ConCePT project, which is partly funded by EFPI A companies and the Innovative Medicine Initiative Joint Undertaking under Grant Agreement No. 115151; the National Institute of 
target volume for dividing these patients into responders and nonresponders.

\section{Introduction}

Progress during recent decades in imaging with positron emission tomography (PET) has improved cancer diagnosis and prognosis by increasing the accuracy of determining and delineating target structures, providing also the tools for individualized 4-dimensional-based radiation therapy (RT) (1). Furthermore, PET imaging has also been used for detecting the residual metabolically active tumor mass after treatment and hence for posttreatment evaluation of its effectiveness $(2,3)$.

For lung cancer patients in particular, contrast-enhanced computed tomography (CT) imaging in combination with ${ }^{18}$ F-fludeoxyglucose (FDG) PET scans is the most widely used imaging technique for staging and delineating the targets $(4,5)$. Extensive work has been done on assessing the predictive potential of pretreatment FDG-PET and the prognostic potential of imaging after the completion of chemoradiation therapy, radiation therapy, or both for poor treatment response (6-12). Fewer studies, however, have investigated the potential of assessing the response of the target to the treatment by monitoring the changes in FDG uptake at an early timepoint during the course of chemoradiation therapy (13-17). A recent study (18) showed that a decrease in metabolic activity of the primary tumor calculated as the difference between the averaged standardized uptake value (SUV) before the start of the treatment and the average SUV determined as early as the second week of treatment was predictive of 2-year overall survival.

The aim of the present study was to perform a systematic evaluation of the tumor response for non-small cell lung cancer (NSCLC) patients previously treated with chemoradiation therapy to determine the potential of repeated FDG-PET CT images for early identification of responders and nonresponders and thus for identifying patients who might benefit from treatment adaptation.

\section{Methods and Materials}

\section{Patient treatment protocol and PET-CT image acquisition}

Twenty-six NSCLC patients treated with radical radiation therapy at the Department of Radiation Oncology
(MAASTRO clinic), Maastricht University Medical Center, The Netherlands were included in the analysis (18-20). Patients underwent radiation therapy with either sequential or concurrent chemotherapy. Patients treated with the sequential regimen received 3 cycles of cisplatin-gemcitabine before starting the radiation treatment, and patients treated in the concurrent regimen received 1 cycle of cisplatin-vinorelbine followed by concomitant chemoradiation therapy with the remaining $2 \mathrm{cy}-$ cles of chemotherapy delivered during radiation treatment. For the sequential group, the radiation therapy delivered 2 fractions of 1.8 Gy per day either up to a total prescribed maximum dose of 79.2 Gy or up to the limit of the tolerated normal tissue toxicity. For the concurrent group, a dose escalation protocol was chosen with 30 fractions of 1.5 Gy 2 times per day delivered first, followed by $2 \mathrm{~Gy}$ fractions once per day up to either the prescribed maximum dose of $69 \mathrm{~Gy}$ or to normal tissue toxicity limit. The relevant patient characteristics are listed in Table 1.

All patients included in this study were imaged in radiation therapy position with FDG-PET CT before the treatment and during the second week of radiation treatment, the time interval ranging from 8 to 13 days. The pretreatment FDG-PET CT images were acquired after 1 cycle and 3 cycles of chemotherapy in the concurrent and sequential regimens, respectively. The PET CT images were acquired with a Biograph 40 PET camera (Siemens Medical Solutions). The injected FDG activity in MBq was calculated as 4 times the body weight in $\mathrm{Kg}$ plus 20 additional MBq (18).

\section{RayStation and image registration}

The 2 available datasets of reconstructed PET-CT images for each patient were imported in a research version of RayStation (RaySearch Laboratories AB). A voxel-to-voxel mapping was achieved by registering the 2 PET-CT images acquired at the 2 different timepoints, after which a PET-on-PET voxel interpolation was performed. A hybrid deformable registration method, which combines an image-based algorithm and one that uses anatomic information provided by the contoured datasets, was used (21).

\section{Effective tumor radiation sensitivity}

The variations of the FDG SUV in the target volume of the paired PET image datasets were analyzed. It was assumed 
Table 1 Characteristics of the patients in the study

\begin{tabular}{|c|c|c|c|c|c|c|c|}
\hline No. & TNM & Stage & No. of $f x$ at PET2 & Dose/fx (Gy) & OS at 2 years & $\bar{\alpha}_{e f f}, \mathrm{~Gy}^{-1}$ & $f_{\bar{\alpha}_{e f f}}, \%$ \\
\hline \multicolumn{8}{|c|}{ Radiation therapy + sequential chemotherapy } \\
\hline 1 & $\mathrm{~T} 2 \mathrm{~N} 2 \mathrm{M} 0$ & IIIa & 13 & 1.8 & 1 & 0.006 & 28 \\
\hline 2 & T3N3M0 & IIIb & 13 & 1.8 & 0 & 0.001 & 41 \\
\hline 3 & T3N2M0 & IIIa & 13 & 1.5 & 1 & 0.012 & 19 \\
\hline 4 & T2N3M0 & IIIb & 13 & 1.5 & 1 & -0.001 & 55 \\
\hline 5 & T1N3M0 & IIIb & 13 & 1.5 & 1 & 0.034 & 0 \\
\hline 6 & T2N2M0 & IIIa & 19 & 1.8 & 0 & 0.000 & 47 \\
\hline 7 & T4N2M0 & IIIb & 15 & 1.5 & 0 & 0.003 & 38 \\
\hline 8 & T4N2M0 & IIIb & 11 & 1.5 & 0 & -0.003 & 63 \\
\hline 9 & T1N2M0 & IIIa & 17 & 1.5 & 1 & 0.015 & 2 \\
\hline 10 & T2N2M0 & IIIa & 13 & 1.8 & 0 & -0.006 & 73 \\
\hline 11 & $\mathrm{~T} 2 \mathrm{~N} 2 \mathrm{M} 0$ & IIIa & 11 & 1.5 & 1 & 0.029 & 15 \\
\hline 12 & T4N0M0 & IIIb & 11 & 1.5 & 1 & 0.011 & 25 \\
\hline 13 & $\mathrm{~T} 2 \mathrm{~N} 3 \mathrm{M} 0$ & IIIb & 12 & 1.5 & 0 & -0.008 & 65 \\
\hline 14 & T4N2Mn.i. & IIIb & 13 & 1.8 & 0 & -0.007 & 84 \\
\hline 15 & $\mathrm{~T} 2 \mathrm{~N} 2 \mathrm{M} 0$ & IIIa & 13 & 1.8 & 1 & 0.001 & 49 \\
\hline \multicolumn{8}{|c|}{ Radiation therapy + concurrent chemotherapy } \\
\hline $16^{*}$ & T1N0M0 & Ia & 12 & 1.5 & 1 & 0.020 & 20 \\
\hline $17^{*}$ & T3N2M0 & IIIa & 12 & 1.5 & 1 & 0.022 & 12 \\
\hline 18 & $\mathrm{~T} 2 \mathrm{~N} 2 \mathrm{M} 0$ & IIIa & 13 & 1.5 & 1 & 0.008 & 28 \\
\hline 19 & $\mathrm{~T} 2 \mathrm{~N} 2 \mathrm{M} 0$ & IIIa & 8 & 1.5 & 0 & -0.011 & 76 \\
\hline 20 & T4N0M0 & IIIb & 17 & 1.5 & 1 & 0.010 & 11 \\
\hline 21 & T4N3M0 & IIIb & 17 & 1.5 & 1 & -0.001 & 55 \\
\hline 22 & T1N2M0 & IIIa & 11 & 1.5 & 1 & 0.007 & 23 \\
\hline 23 & $\mathrm{~T} 2 \mathrm{~N} 3 \mathrm{M} 0$ & IIIb & 13 & 1.5 & 1 & 0.005 & 32 \\
\hline 24 & $\mathrm{~T} 2 \mathrm{~N} 2 \mathrm{M} 0$ & IIIa & 17 & 1.5 & 0 & 0.004 & 33 \\
\hline 25 & T1N2M0 & IIIa & 11 & 1.5 & 0 & 0.001 & 32 \\
\hline 26 & $\mathrm{~T} 2 \mathrm{~N} 3 \mathrm{M} 0$ & IIIb & 10 & 1.5 & 0 & -0.006 & 73 \\
\hline 27 & T3N0M0 & $\mathrm{IIb}$ & 11 & 1.5 & 1 & 0.008 & 24 \\
\hline
\end{tabular}

Abbreviations: $\mathrm{fx}=$ fractions; OS $=$ overall survival; PET2 $=$ second positron emission tomography scan.

* 16 and 17 refer to the same patient with two primary tumors.

that for each voxel a variation in the activity uptake reflects a change in the density of functional clonogenic cells resulting from cell kill by radiation. An operational parameter for radiosensitivity, $\alpha_{e f f}$, can be determined from the quotient of the 2 PET image values and the planned delivered dose distribution under the linear quadratic formalism (22) for cell killing (equation 1):

$$
\alpha_{e f f}(\boldsymbol{r})=\frac{\ln \left[\frac{P E T_{1}(\boldsymbol{r})}{P E T_{2}(\boldsymbol{r})}\right]}{n d(\boldsymbol{r})\left[1+\frac{d(\boldsymbol{r})}{(\alpha / \beta)}\right]},
$$

where $P E T_{1}(\boldsymbol{r})$ and $\operatorname{PET}_{2}(\boldsymbol{r})$ are the SUV values in voxel $\mathbf{r}$ of the PET images acquired before and during the second week of radiation treatment, and $d(\boldsymbol{r})$ and $n$ are the dose per fraction and the number of fractions delivered until the second PET image. An $\alpha / \beta=10$ Gy was assumed for the tumor cells.

A schematic illustration of the method is given in Figure 1.

This voxel-based analysis in the target volume leads to a distribution of effective radiosensitivity values for which one could calculate the average effective radiation sensitivity, $\bar{\alpha}_{e f f}$, and the fraction of voxels having negative effective radiation sensitivity, $f_{\alpha_{e f f}}$.

\section{Statistical analysis and cross-validation}

Correlations were sought between the derived $\bar{\alpha}_{e f f}$, or the fraction of negative $\alpha_{\text {eff }}$ values in the distribution, $f_{\alpha_{e f f}}$, and the overall patient survival at 2 years. Separate analyses were performed for the primary gross target volume $\left(\mathrm{GTV}_{\text {prim }}\right)$, the lymph node GTV $\left(\mathrm{GTV}_{\text {lymph }}\right)$, the primary clinical target volume $\left(\mathrm{CTV}_{\text {prime }}\right)$, and the lymph node CTV $\left(\mathrm{CTV}_{\text {lymph }}\right)$. The statistical analysis was done on subsets of patients depending on the administration of radiation therapy in relation to chemotherapy.

Commercial software, MedCalc, version 13.1.0.0 (MedCalc Software), was used to generate receiver operating characteristic (ROC) curves to determine the optimal threshold that would correlate best with the overall 2-year survival. The optimal criterion was determined as the value with highest specificity and sensitivity according to the ROC curve. The accuracy of the prediction was quantified in terms of area under the curve (AUC). The method by DeLong and co-authors (23) was selected for the calculation of the standard error of the AUC. 


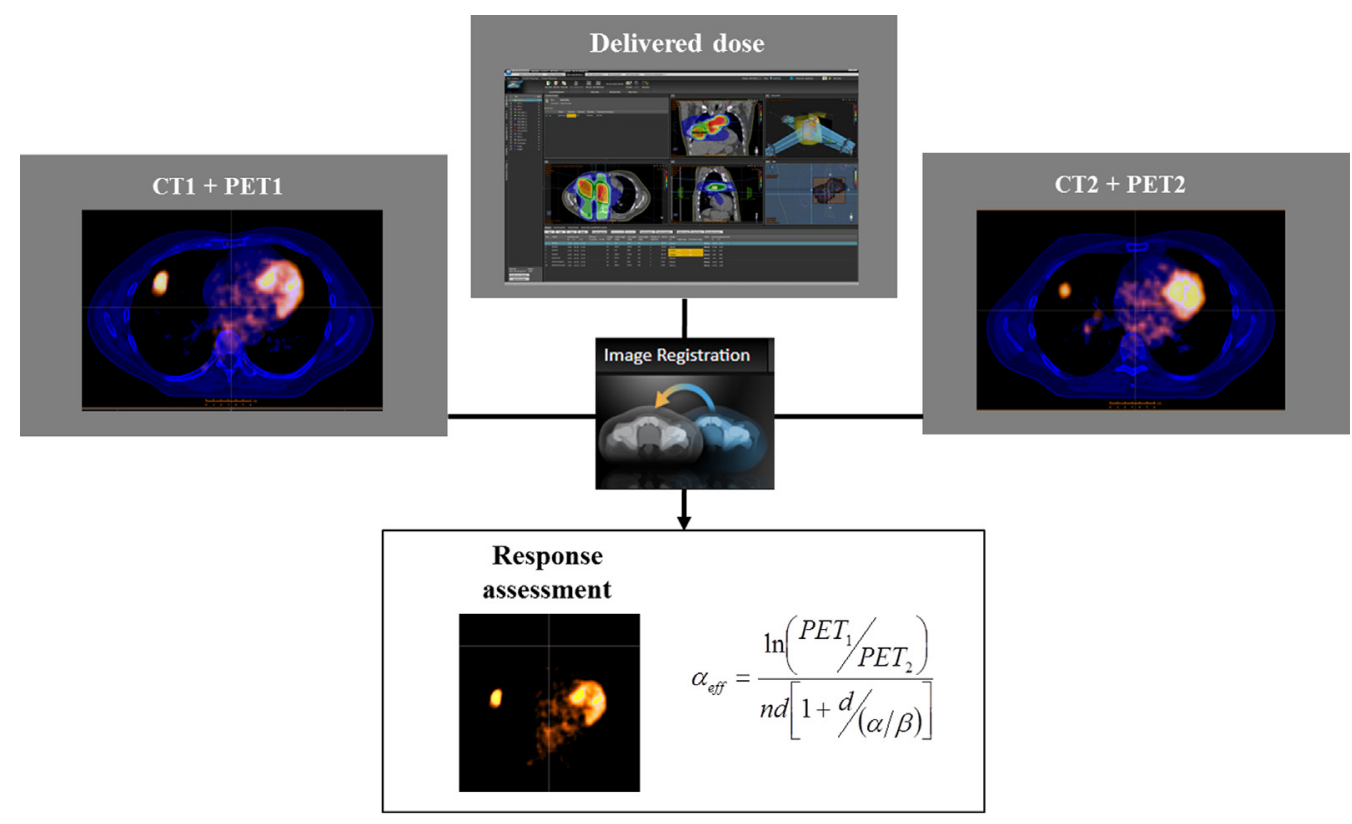

Fig. 1. Illustration of the method used for the assessment of the tumor response based on 2 successive ${ }^{8} \mathrm{~F}$-fludeoxyglucose positron emission tomography (FDG-PET) images in relation to the dose delivered by the time of the second FDG-PET acquisition. The baseline hypothesis is that the FDG uptake in the PET image is proportional with the density of the clonogenic cells. $\mathrm{CT}=$ computed tomography.

To validate the predictive value of the method on an independent dataset, the findings were also subjected to a crossvalidation procedure. Given the small dataset available, the "leave-one-out" cross-validation method was chosen (24). An in-house MATLAB version 7.13 (MathWorks, Inc) code was written to perform the analysis. The leave-one-out method divides the data into 2 mutually exclusive datasets. A logistic regression model is fitted on a validation dataset consisting of the entire dataset minus 1 observation, and the fitting parameters of the model are used to evaluate the single observation left outside (the training set). The procedure is repeated for all the observations in the considered dataset. The AUC values of the recalculated ROC curves and corresponding $P$ values are reported and reviewed.

\section{Robustness analysis with respect to image registration}

The method for assessing tumor responsiveness to treatment based on 2 successive FDG-PET CT images was tested for robustness with respect to the registration by adding a translation error to the transformation matrix of the CT-to-CT registration. Thus, the calculation of the $\alpha_{\text {eff }}$ values at voxel level was redone for 3 different cases when the second PET image was rigidly translated with $5 \mathrm{~mm}$ in the anteroposterior direction, the left-right direction, and the craniocaudal direction, respectively. The test aimed to check whether $\bar{\alpha}_{\text {eff }}$ and $f_{\alpha_{e f f}}$ corresponding to the new distributions of $\alpha_{\text {eff }}$ values resulting after the translations would render similar correlation trends with the overall patient survival at 2 years, as in the case of no systematic translations.

\section{Results}

\section{Identification of tumor response patterns}

Figure 2 shows the CT and PET images at the 2 mentioned timepoints, and the distributions of effective radiosensitivities derived with equation 1 in the $\mathrm{GTV}_{\text {prim }}$ for 3 patients considered representative of the tumor response patterns identified in the analyzed patient group. The upper panel shows the case of a patient with lower SUVs in all GTV voxels at the time of the second PET-CT scan, after the delivery of 13 fractions of $1.5 \mathrm{~Gy}$, in comparison with the SUVs in the corresponding voxels before the start of treatment. The resulting values of $\alpha_{\text {eff }}$ are all positive, indicating a decrease of the number of clonogenic cells in each voxel. The patient was alive 2 years after treatment. The middle panel shows the case of a patient with a majority of negative $\alpha_{\text {eff }}$ values in the resulting distribution, who did not survive 2 years after treatment. The lower panel shows the case of a patient with a more complex distribution of $\alpha_{\text {eff }}$ values, mostly positive, who was alive at 2 years after treatment. The other patients exhibited distributions of $\alpha_{\text {eff }}$ values that were largely encompassed by these patterns.

\section{Average $\alpha_{\text {eff }}$ and the fraction of voxels having negative $\alpha_{\text {eff }}$}

Given the resultant distributions of effective radiosensitivities, correlations were sought between the survival at 2 years after chemoradiation therapy and the calculated 

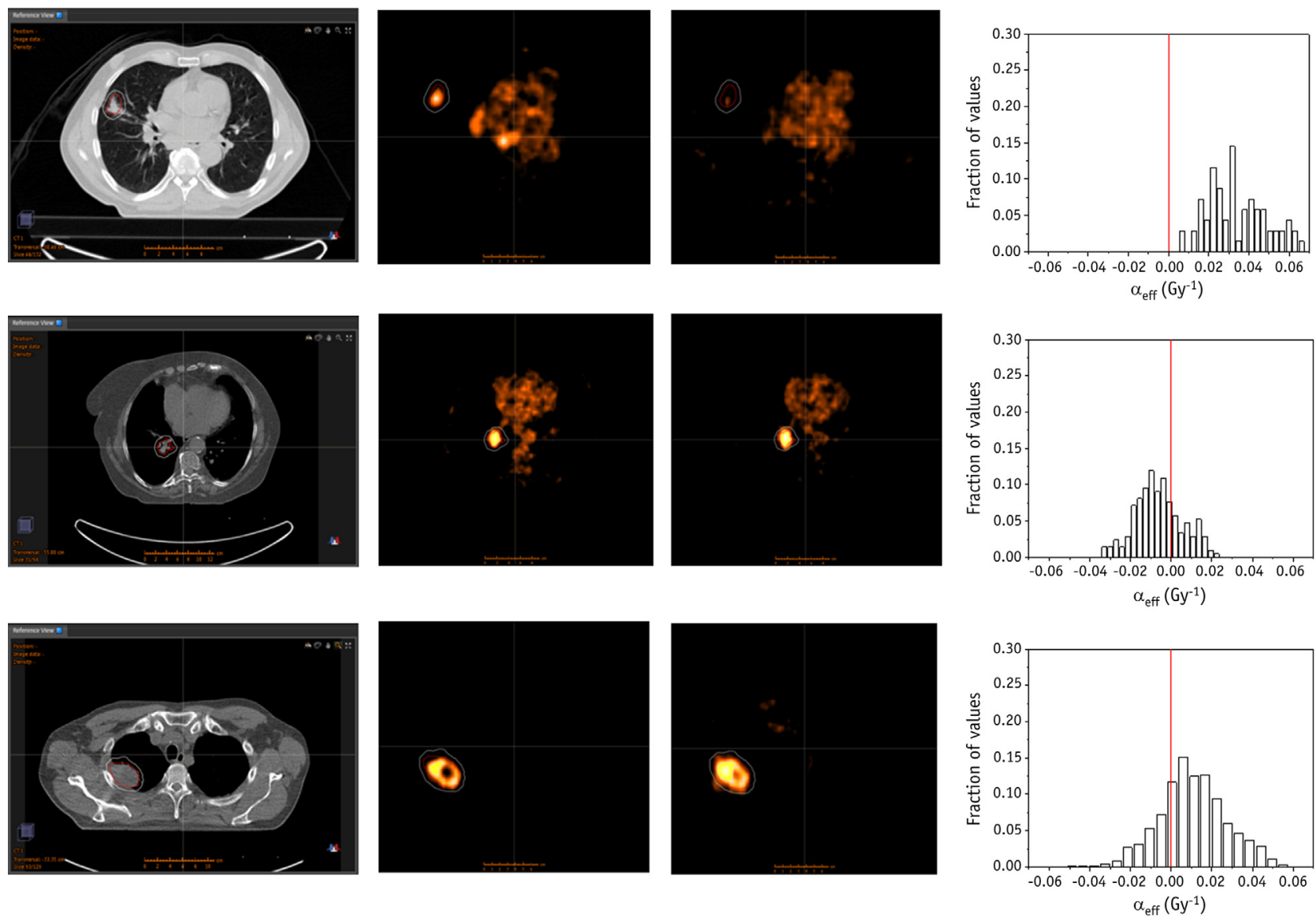

Fig. 2. Computed tomographic images, 2 successive positron emission tomographic (PET) images, and the distribution of the effective radiosensitivity, $\alpha_{\text {eff }}$, in the clinical target volume of the primary tumor $\left(\mathrm{GTV}_{\text {prim }}\right)$ volume for 3 selected patients. The $\mathrm{CTV}_{\text {prim }}$ is contoured in white and the gross tumor volume of the primary tumor in red. The upper panels show the distributions of the effective radiosensitivities in a patient with good response to the treatment assessed as survival at the 2-year follow-up visit: a decrease in the ${ }^{8} \mathrm{~F}$-fludeoxyglucose uptake is noticed in the second PET image compared with the first PET acquisition. The middle panels correspond to a patient with poor response: the uptake of the tracer in the second PET image shows an increase in comparison with the first PET image. The lower panels describe a patient with good response: the uptake of the tracer in the second PET image indicates enhanced tracer perfusion in comparison with the first PET image.

average effective radiation sensitivity, $\bar{\alpha}_{\text {eff }}$, or the fraction of voxels having negative effective radiation resistance, $f_{\alpha_{\text {eff }}}$.

The analysis was performed by stratifying the ensemble according to the type of chemoradiation therapy (ie concurrent or sequential chemotherapy). The corresponding values for the $\bar{\alpha}_{\text {eff }}$ and $f_{\alpha_{\text {eff }}}$ for the patients included in the analysis are shown in Table 1.

The ROC analysis for the patients treated with RT and sequential chemotherapy revealed that the method for dividing the patients into responders and nonresponders was statistically significant $(P<.0001)$, with a sensitivity of $75 \%$ and a specificity of $100 \%$, both when $\bar{\alpha}_{e f f}$, and $f_{\alpha_{e f f}}$ were used as criteria. Thus, all nonresponders were correctly identified, and $25 \%$ of the responders were misidentified as nonresponders.

For the patients treated with RT and concurrent chemotherapy, a sensitivity of $87 \%$ with $100 \%$ specificity was found based on $\bar{\alpha}_{\text {eff }}$, and the analysis was statistically significant $(P<.0001)$. Choosing $f_{\alpha_{e f f}}$ as a criterion, the method showed a sensitivity of $75 \%$ and a specificity of $100 \%(P<.001)$.

These findings are summarized in Figure 3, where the ROC curves show the correlation between $\bar{\alpha}_{\text {eff }}$ and the treatment outcome and also the correlation between $f_{\alpha_{e f f}}$ and the treatment outcome for the 2 groups of patients ( 15 and 12 cases are included in the sequential and concurrent group, respectively) in the GTV of the primary tumor. The corresponding AUC and the $P$ value are indicated on each figure.

A similar analysis was performed for the distribution of the effective radiosensitivity at voxel level in the GTV of the involved mediastinal lymph nodes, $G V_{\text {lymph. }}$. The trends observed for the primary GTV were maintained only with respect to the specificity of the method, but the statistical significance in this case was very low (Table 2).

The analysis was extended to include the contribution of the CTV-to-GTV margins for the primary tumor and the 
lymph nodes, and the results are also summarized in Table 2. The correlation of the responsiveness of the node target volumes with the treatment outcome lacks statistical significance, as does the distribution of the effective sensitivity in the CTVs.

\section{Cross-validation and $\mathrm{CT}$ translational registration robustness test}

Given the low number of patients available for this study, the results were subjected to a cross-validation analysis using the "leave-one-out" method (24). The results of the cross-validation showed that dividing the patients into good responders and poor responders based on the assessment of the effective radiosensitivity rendered statistically significant results with a sensitivity and a specificity larger than $75 \%$, only for the patients treated with RT and sequential chemotherapy, when the fraction of negative radiosensitivities, $f_{\alpha_{e f f}}$, was chosen as the selection criterion. The recalculated AUC value after cross-validation was approximately 0.86 , with a $P$ value equal to 0.0002 .

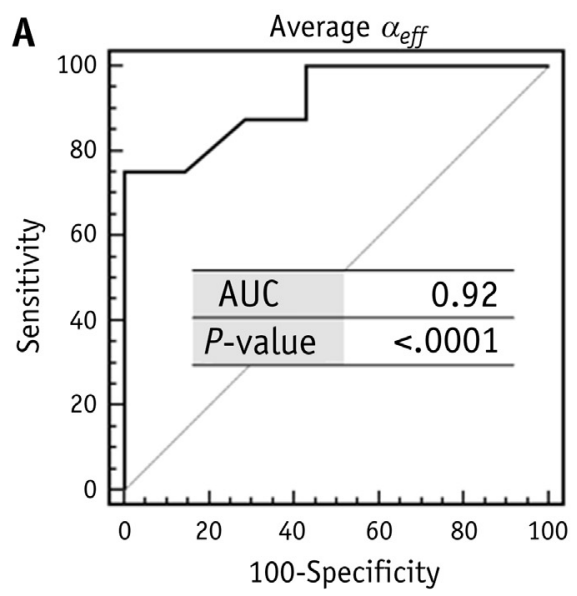

C

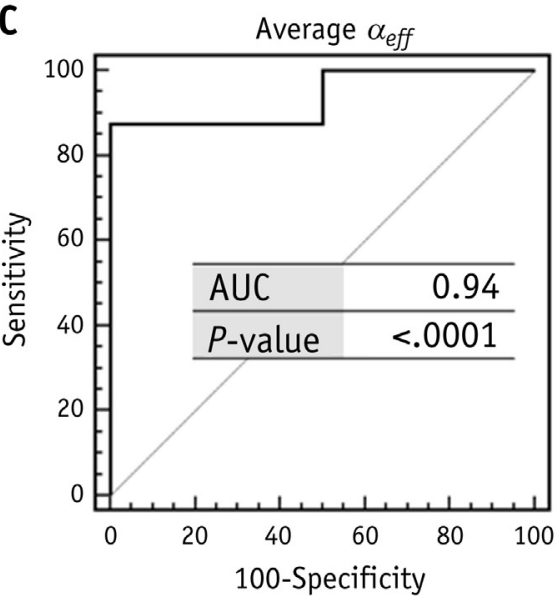

As part of the robustness analysis of the described method to the quality of image registration, $\alpha_{\text {eff }}$ distributions were recalculated after independent rigid translations of $5 \mathrm{~mm}$ in the anteroposterior, craniocaudal, and lateral directions introduced in the registration matrix for the 2 datasets. The repeated analysis of the new resultant $\alpha_{\text {eff }}$ distributions largely showed the same trends with respect to the AUC and $P$ values.

\section{Discussion}

The FDG-PET method has improved staging and influenced treatment for NSCLC by reducing interobserver variability in target delineation (25). Pretreatment values characterizing the uptake of the PET tracer have also proved to have prognostic values for patients with lung cancer undergoing surgery (2). PET imaging has also been used for posttreatment assessment by investigating the metabolic activity of the residual mass at the end of treatment (26). Nevertheless, a large but not sufficiently explored potential of PET lies in characterizing subtle
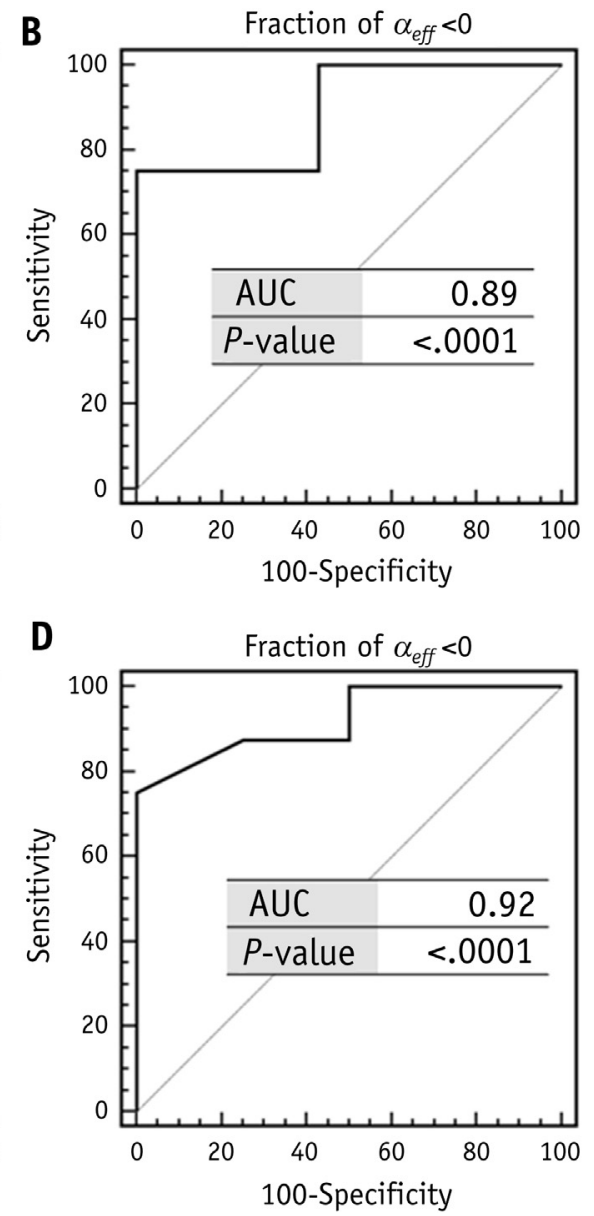

Fig. 3. Receiver operating characteristics curves showing the correlation between the average $\alpha_{\text {eff }}$ and the treatment outcome and also the correlation between the fraction of negative $\alpha_{\text {eff }}$ in the gross tumor volume of the primary tumor and the treatment outcome for the 2 groups of patients receiving radiation therapy and sequential chemotherapy (a and b) and radiation therapy and concurrent chemotherapy ( $c$ and d). The corresponding area under the curve (AUC) and the $P$ value are indicated in each case. 
Table 2 Summary of the ROC analysis for various target volumes

\begin{tabular}{|c|c|c|c|c|c|c|c|c|c|c|}
\hline \multirow[b]{2}{*}{ Target } & \multicolumn{5}{|c|}{ ROC analysis based on $\alpha_{\text {eff }}$} & \multicolumn{5}{|c|}{ ROC analysis based on $f_{\bar{\alpha}_{e f f}}$} \\
\hline & Sensitivity & Specificity & AUC & $P$ value & Criterion & Sensitivity & Specificity & AUC & $P$ value & Criterion \\
\hline \multicolumn{11}{|c|}{ Radiation therapy + sequential chemotherapy } \\
\hline $\mathrm{GTV}_{\text {prim }}$ & 75 & 100 & 0.92 & $<.0001$ & $>0.003$ & 75 & 100 & 0.89 & $<.0001$ & $\leq 0.3$ \\
\hline $\mathrm{GTV}_{\text {lymph }}$ & 67 & 100 & 0.72 & .2 & $>-0.001$ & 67 & 100 & 0.71 & .3 & $\leq 0.5$ \\
\hline $\mathrm{CTV}_{\text {prim }}$ & 67 & 100 & 0.85 & .0003 & $>0.001$ & 67 & 100 & 0.86 & .0003 & $\leq 0.4$ \\
\hline $\mathrm{CTV}_{\text {lymph }}$ & 50 & 100 & 0.61 & 6 & $>-0.002$ & 50 & 100 & 0.75 & .1 & $\leq 0.4$ \\
\hline \multicolumn{11}{|c|}{ Radiation therapy + concurrent chemotherapy } \\
\hline $\mathrm{GTV}_{\text {prim }}$ & 87 & 100 & 0.94 & $<.0001$ & $>0.004$ & 75 & 100 & 0.92 & $<.0001$ & $\leq 0.3$ \\
\hline GTV $_{\text {lymph }}$ & 20 & 50 & 0.53 & .9 & $>-0.007$ & 80 & 50 & 0.55 & .8 & $>0.3$ \\
\hline $\mathrm{CTV}_{\text {prim }}$ & 100 & 75 & 0.88 & .004 & $>-0.005$ & 100 & 75 & 0.86 & .005 & $\leq 0.6$ \\
\hline $\mathrm{CTV}_{\text {lymph }}$ & 80 & 50 & 0.53 & .9 & $>-0.007$ & 100 & 25 & 0.55 & .8 & $>0.2$ \\
\hline
\end{tabular}

Abbreviations: $\mathrm{AUC}=$ area under the curve; $\mathrm{CTV}_{\text {lymph }}=$ lymph node clinical target volume; $\mathrm{CTV}_{\text {prim }}=$ primary clinical target volume; $\mathrm{GTV}_{\text {lymph }}=1 \mathrm{ymph}$ node gross target volume; $\mathrm{GTV}_{\text {prim }}=$ primary gross target volume; $\mathrm{ROC}=$ receiver operating characteristics.

Average $\alpha_{\text {eff }}$ values in the $\mathrm{GTV}_{\text {prim }}, \mathrm{GTV}_{\text {lymph }}, \mathrm{CTV}_{\text {prim }}$, and $\mathrm{CTV}_{\text {lymph }}$, respectively, and the fraction of negative $\alpha_{\text {eff }}$ values were correlated with the overall patient survival at 2 years. The results corresponding to sensitivity and specificity values $>75 \%$ that are also statistically significant based on the $P$ value of the AUC are shown in italics. Those results that remained statistically significant after cross-validation with the "leave-one-out" method are shown in bold italics.

changes in metabolic activity of tumor cells long before morphologic changes become visible. From this point of view, PET could offer an insight into the early response to treatment and thus open new directions for treatment adaptation and for other strategies for treatment individualization. It was the aim of the present study to explore this aspect, taking into account not only changes in PET tracer uptake but also the dose delivered and its distribution across the tumor. The study was based on an early assessment of tumor response to radiation treatment, to avoid possible interference from the reduced number of surviving cells or radiation-induced inflammatory processes that may be induced at later timepoints. In this respect, the present study differs from earlier attempts to characterize the in-treatment response of the tumors after more than half of the radiation treatment has been delivered $(13,14)$.

Another novelty of the present study was that it used a voxel-based analysis of tumor response, taking into account not only the initial regional uptake of the PET tracer but also the local dose delivered to the tumor until the intreatment PET investigation. Many other studies of the topic $(15-17,19)$ have used global parameters to characterize tumor uptake, and this reduced the sensitivity and specificity of the identified trends, thus mirroring the large intraindividual heterogeneity and different patterns assessed for metabolic responders and nonresponders. The definition of $\alpha_{\text {eff }}$ used in this study implicitly entails that the FDG uptake in the PTV decreases at the second timepoint with respect to the level registered at the start of the treatment $\left(\mathrm{PET}_{1}>\mathrm{PET}_{2}\right)$. Hence, for negative $\alpha_{\text {eff }}$ it is possible that cell proliferative processes have a larger effect than the cell depletion caused by the treatment. However, it has to be mentioned that the numeric resulting values of $\alpha_{\text {eff }}$ expressed in $\mathrm{Gy}^{-1}$ reported in this study cannot be used in a straightforward calculation for determining the surviving fraction of cells in the tumor using the linear quadratic model. The low values of $\alpha_{\text {eff }}$ appear to confirm the previously postulated hypothesis of the dominant presence at the time of the second FDG-PET image of cells taking up the glucose-analog tracer but doomed to eventually die of radiation damage (27). The determined $\alpha_{\text {eff }}$ values would also relate to the complexity and the dynamics of the tumor microenvironment.

Given the size of the analyzed population, some concerns were raised with respect to the risk of overfitting the training data with the proposed model. Consequently, the proposed approach was subjected to a cross-validation analysis using the leave-one-out method to minimize this risk. The analysis showed that the approach maintained high sensitivity and specificity and even the statistical significance for a subgroup of patients. These are promising results and warrant a future external validation of the proposed approach. Further sources of concern in applying the method proposed in this study might be related to changes in tumor size and shape during the time between the 2 PET scans. However, the early assessment of the response as proposed in this report might prevent very large changes. Indeed, for the population of patients included in this study, no large differences were observed, in either the volume or displacement of the primary tumor or the lymph nodes (20). However, further investigations are warranted and planned to test the method for other tumor types and locations prone to large geometric changes, such as the head and neck.

The strong correlation between the change in PET uptake in the primary GTV and the overall survival at 2 years shows the importance of controlling the primary disease to improve patient survival. This is in contrast to the findings of Hoang et al (27), who suggested that early treatment response in head and neck cancers should be measured quantitatively in nodal disease rather than the primary tumor, although their findings might in fact reflect the use of global parameters to characterize tumor response. Our 
findings nevertheless suggest that overall control could be improved through strategies aimed at increasing the control of the primary tumors. Thus, the best results would probably be obtained if poorly responding patients were identified early during the treatment, given that salvage therapies after completion of the initial treatment would fail to improve the outcome.

Monitoring the early response of tumors is very efficient for treatment adaptation and individualization and has the potential to identify the candidates for more aggressive strategies like dose escalation or combined therapies to increase local control rates $(28,29)$. More advanced image analysis approaches (30-32) are likely to further improve the performance of such analyses. The voxel-based method proposed in this study offers a practical approach toward achieving this aim and also appears to have quite high potential in identifying the patients responding to the standard treatment, thus avoiding unnecessarily exposing them to aggressive therapies that could increase the risk of severe side effects.

\section{Conclusions}

The evaluation of the early response for the 26 NSCLC cancer patients showed that it is feasible to determine threshold parameters based on the effective radiosensitivities of the patients corresponding, respectively, to good and poor responses.

\section{References}

1. Senan S, De Ruysscher D. Critical review of PET-CT for radiotherapy planning in lung cancer. Crit Rev Oncol Hematol 2005;56:345-351.

2. Zhang H, Wroblewski K, Liao S, et al. Prognostic value of metabolic tumor burden from (18)F-FDG PET in surgical patients with non-small-cell lung cancer. Acad Radiol 2013;20:32-40.

3. Obara P, Pu Y. Prognostic value of metabolic tumor burden in lung cancer. Chin J Cancer Res 2013;25:615-622.

4. Hicks RJ, Kalff V, MacManus MP, et al. (18)F-FDG PET provides high-impact and powerful prognostic stratification in staging newly diagnosed non-small cell lung cancer. J Nucl Med 2001;42: 1596-1604.

5. Annema JT, Hoekstra OS, Smit EF, et al. Towards a minimally invasive staging strategy in NSCLC: Analysis of PET positive mediastinal lesions by EUS-FNA. Lung Cancer 2004;44:53-60.

6. Abramyuk A, Tokalov S, Zophel K, et al. Is pre-therapeutical FDG-PET/CT capable to detect high risk tumor subvolumes responsible for local failure in non-small cell lung cancer? Radiother Oncol 2009;91:399-404.

7. Aerts HJ, Bosmans G, van Baardwijk AA, et al. Stability of $18 \mathrm{~F}$-deoxyglucose uptake locations within tumor during radiotherapy for NSCLC: A prospective study. Int J Radiat Oncol Biol Phys 2008; 71:1402-1407.

8. Mac Manus MP, Hicks RJ, Matthews JP, et al. Positron emission tomography is superior to computed tomography scanning for response-assessment after radical radiotherapy or chemoradiotherapy in patients with non-small-cell lung cancer. J Clin Oncol 2003;21: $1285-1292$.

9. Aerts HJ, van Baardwijk AA, Petit SF, et al. Identification of residual metabolic-active areas within individual NSCLC tumours using a pre-radiotherapy (18)Fluorodeoxyglucose-PET-CT scan. Radiother Oncol 2009;91:386-392.

10. Carvalho S, Leijenaar RT, Velazquez ER, et al. Prognostic value of metabolic metrics extracted from baseline positron emission tomography images in non-small cell lung cancer. Acta Oncol 2013; 52:1398-1404.

11. Aerts HJ, Bussink J, Oyen WJ, et al. Identification of residual metabolic-active areas within NSCLC tumours using a preradiotherapy FDG-PET-CT scan: A prospective validation. Lung Cancer 2012;75:73-76.

12. van Loon J, van Baardwijk A, Boersma L, et al. Therapeutic implications of molecular imaging with PET in the combined modality treatment of lung cancer. Cancer Treat Rev 2011;37:331-343.

13. Huang W, Zhou T, Ma L, et al. Standard uptake value and metabolic tumor volume of (18)F-FDG PET/CT predict short-term outcome early in the course of chemoradiotherapy in advanced non-small cell lung cancer. Eur J Nucl Med Mol Imaging 2011;38:1628-1635.

14. Kong FM, Frey KA, Quint LE, et al. A pilot study of $[18 \mathrm{~F}]$ fluorodeoxyglucose positron emission tomography scans during and after radiation-based therapy in patients with non small-cell lung cancer. J Clin Oncol 2007;25:3116-3123.

15. Massaccesi M, Calcagni ML, Spitilli MG, et al. (18)F-FDG PET-CT during chemo-radiotherapy in patients with non-small cell lung cancer: The early metabolic response correlates with the delivered radiation dose. Radiat Oncol 2012;7:106.

16. Usmanij EA, de Geus-Oei LF, Troost EG, et al. 18F-FDG PET early response evaluation of locally advanced non-small cell lung cancer treated with concomitant chemoradiotherapy. J Nucl Med 2013;54: 1528-1534.

17. van Baardwijk A, Bosmans G, Dekker A, et al. Time trends in the maximal uptake of FDG on PET scan during thoracic radiotherapy. A prospective study in locally advanced non-small cell lung cancer (NSCLC) patients. Radiother Oncol 2007;82:145-152.

18. van Elmpt W, Ollers M, Dingemans AM, et al. Response assessment using 18F-FDG PET early in the course of radiotherapy correlates with survival in advanced-stage non-small cell lung cancer. J Nucl Med 2012;53:1514-1520.

19. van Elmpt W, Ollers M, Lambin P, et al. Should patient setup in lung cancer be based on the primary tumor? An analysis of tumor coverage and normal tissue dose using repeated positron emission tomography/computed tomography imaging. Int J Radiat Oncol Biol Phys 2012:82:379-385.

20. van Elmpt W, Ollers M, van Herwijnen H, et al. Volume or position changes of primary lung tumor during (chemo-)radiotherapy cannot be used as a surrogate for mediastinal lymph node changes: The case for optimal mediastinal lymph node imaging during radiotherapy. Int $J$ Radiat Oncol Biol Phys 2011;79:89-95.

21. Deformable registration in RayStation. http://www.raysearchlabs.com/ Global/Publications/White\%20papers/White\%20paper\%202\%20-\%20 Deformable\%20(web).pdf. Accessed August 18, 2014.

22. Lea DE, Catcheside DG. The mechanism of the induction by radiation of chromosome aberrations in Tradescantia. J Genet 1942; 44:216-245.

23. DeLong ER, DeLong DM, Clarke-Pearson DL. Comparing the areas under two or more correlated receiver operating characteristic curves: A nonparametric approach. Biometrics 1988;44:837-845.

24. Arlot S, Celisse A. A survey of cross-validation procedures for model selection. Stat Surv 2010;4:40-79.

25. Mah D, Chen CC. Image guidance in radiation oncology treatment planning: The role of imaging technologies on the planning process. Semin Nucl Med 2008;38:114-118.

26. Machtay M, Duan F, Siegel BA, et al. Prediction of survival by [18F] fluorodeoxyglucose positron emission tomography in patients with locally advanced non-small-cell lung cancer undergoing definitive chemoradiation therapy: Results of the ACRIN 6668/RTOG 0235 trial. J Clin Oncol 2013;31:3823-3830.

27. Hoang JK, Das SK, Choudhury KR, et al. Using FDG-PET to measure early treatment response in head and neck squamous cell carcinoma: 
Quantifying intrinsic variability in order to understand treatmentinduced change. AJNR Am J Neuroradiol 2013;34:1428-1433.

28. Lambin P, van Stiphout RG, Starmans MH, et al. Predicting outcomes in radiation oncology-multifactorial decision support systems. Nat Rev Clin Oncol 2013;10:27-40.

29. Oberije C, Nalbantov G, Dekker A, et al. A prospective study comparing the predictions of doctors versus models for treatment outcome of lung cancer patients: A step toward individualized care and shared decision making. Radiother Oncol 2014;112:37-43.
30. Lambin P, Rios-Velazquez E, Leijenaar R, et al. Radiomics: Extracting more information from medical images using advanced feature analysis. Eur J Cancer 2012;48:441-446.

31. Leijenaar RT, Carvalho S, Velazquez ER, et al. Stability of FDG-PET Radiomics features: An integrated analysis of test-retest and inter-observer variability. Acta Oncol 2013;52:1391-1397.

32. Aerts HJ, Velazquez ER, Leijenaar RT, et al. Decoding tumour phenotype by noninvasive imaging using a quantitative radiomics approach. Nat Commun 2014;5:4006. 